\title{
Preoperative measurement of pulmonary vascular resistance in complete transposition of the great arteries
}

\author{
A Bush, C M Busst, W B Knight, J S Carvalho, M L Rigby, E A Shinebourne
}

\begin{abstract}
Transposition of the great arteries is frequently complicated by the early onset of pulmonary vascular disease. It is difficult to measure pulmonary blood flow by the Fick principle because the pulmonary arteriovenous oxygen content difference is small and bronchial blood flow is increased in this condition. In eight patients (mean age $7 \cdot 7$ years, range 3 months to 29 years) with transposition of the great arteries mass spectrometry was used to measure oxygen uptake and predict pulmonary end capillary blood oxygen content. The effects of the bronchial circulation were studied by computer modelling. There was close agreement between pulmonary end capillary and pulmonary vein blood oxygen contents but the resultant percentage difference in arteriovenous content difference was significant (mean (SE of difference)) $(14 \cdot 5(3 \cdot 8) \%)$. The effect of the bronchial circulation was to give spuriously high estimates of pulmonary blood flow. The error was greatest when oxygen consumption was low and aortic blood was very desaturated.
\end{abstract}

Rapidly progressive pulmonary vascular disease is an important complication of transposition of the great arteries. ${ }^{1-3}$ It may occur as early as the first year of life, ${ }^{4-6}$ whether or not the ventricular septum is intact ${ }^{6-8}$ and despite the presence of pulmonary stenosis ${ }^{59}$ or adequate banding of the pulmonary artery. ${ }^{210}$ Assessment of severity is helpful in determining the nature and timing of operation. Measurement of pulmonary vascular resistance may not be reliable in these children because the high pulmonary artery saturation results in a low arteriovenous oxygen content difference. ${ }^{910}$ Accurate determination of this difference is necessary for application of the Fick principle. $^{10-12}$ Furthermore, bronchial artery hypertrophy has been shown angiographically ${ }^{9}$ and histologically, ${ }^{1}$ and an increased bronchial blood flow may affect the measurements. ${ }^{9}$ This paper reports our approach to the preoperative measurement of pulmonary blood flow in these children. We also discuss how reliable such measurements are likely to be. This assessment was based in part on computer modelling of the pulmonary and bronchial circulation.
Patients and methods

We report nine haemodynamic studies in eight patients. There were five male patients and three female patients, mean age $7 \cdot 7$ years, range three months to 29 years. All had transposition of the great arteries with communications between the circulations at atrial or ventricular level. Table 1 shows the full details. No patient had a ductus arteriosus at the time of the study. In all oxygen saturation was higher in the pulmonary artery than in the aorta. Patient 1 was studied on two occasions, three months apart, because of fears that pulmonary vascular disease had developed while he was awaiting operation. Flow was measured at diagnostic cardiac catheterisation while the patients were intubated and ventilated. Full details of the methods have been published elsewhere. ${ }^{13-15}$

In summary, fluid filled catheters were introduced percutaneously into the femoral artery and vein and positioned in the aorta and pulmonary artery respectively. For the measurements of pulmonary blood flow, oxygen consumption was measured by mass spectrometry (MGA 200), by the steady state, argon dilution principle. ${ }^{13}$ Blood $\mathrm{Po}_{2}, \mathrm{pH}$, and base excess were measured on a Corning 165 blood gas analyser and used to calculate blood oxygen contents. ${ }^{16} \mathrm{We}$ assumed that the solubility of free oxygen in blood was $0.03 \mathrm{ml} /$ $\mathrm{mm} \mathrm{Hg} / \mathrm{l}$. End tidal $\mathrm{PCO}_{2}$ was measured with the mass spectrometer and used to calculate the alveolar $\mathrm{PO}_{2}$ from the alveolar air equation. This value was then used to calculate the oxygen content of pulmonary end capillary blood, which replaced the oxygen content of the pulmonary vein in the Fick equation. Whenever possible, we also sampled the pulmonary vein to check the validity of our assumption that the oxygen contents of the

Table 1 Additional diagnoses in patients with complete transposition of the great arteries

\begin{tabular}{llll}
\hline No & Age $(y r)$ & Sex & Diagnoses \\
\hline 1 & $3 / 12$ & $\mathrm{M}$ & VSD/PS \\
2 & $7 / 12$ & $\mathrm{M}$ & ASD \\
3 & $8 / 12$ & $\mathrm{M}$ & ASD/VSD \\
4 & $21 / 12$ & $\mathrm{~F}$ & VSD/PAB/Coarc/DA \\
5 & $26 / 12$ & $\mathrm{~F}$ & VSD/PAB \\
6 & 10 & $\mathrm{M}$ & PAB/TR \\
7 & 17 & $\mathrm{M}$ & PAB/VSD \\
8 & 29 & $\mathrm{~F}$ & VSD
\end{tabular}

ASD, atrial septal defect; Coarc, coarctation; DA, ductus arteriosus (closed surgically before the study); PAB, pulmonary artery band; PS, pulmonary stenosis; TR, tricuspid regurgitation; VSD, ventricular septal defect. 


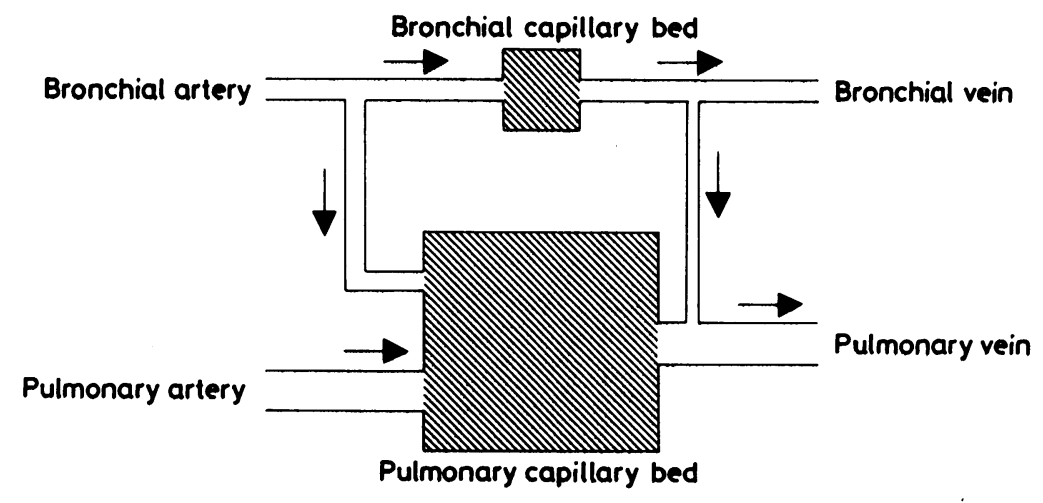

Figure 1 The blood supply to the lungs, as modelled in this paper. The bronchial arterial tree supplies both alveolar and bronchial capillaries; the bronchial capillaries drain into both bronchial and pulmonary veins.

pulmonary vein and pulmonary end capillary are similar.

COMPUTER MODEL

Bronchial artery blood flow cannot easily be measured in humans. The model (fig 1) therefore arbitrarily allocates values which increase from zero in steps of $100 \mathrm{ml} / \mathrm{min}$ per $\mathrm{m}^{2}$. The oxygen content of bronchial artery blood equals that of aortic blood. Because it is desaturated, this stream of blood may be able to take up oxygen, particularly if it perfuses alveolar capillaries through precapillary anastomoses with the pulmonary circulation. This bronchial blood oxygen uptake would be indistinguishable from uptake of oxygen by blood in the pulmonary circulation. Therefore in the Fick equation used in the calculation of pulmonary artery blood flow, the numerator (pulmonary blood oxygen uptake) is overestimated. The effects of this can be modelled if the oxygen content of bronchial venous blood is known. In healthy individuals, approximately one third of the bronchial circulation drains into the right atrium via the bronchial veins, and two thirds drains into the left atrium via the pulmonary veins. ${ }^{17}$ In neither route can bronchial venous oxygen content be measured, nor can it be assumed to be equal to that of vena caval blood. Bronchial venous blood cannot be more oxygenated than pulmonary end capillary blood whatever route it takes, so the two are assumed to be equal. If any bronchial venous blood is less saturated than pulmonary end capillary blood, then the uptake of oxygen by the bronchial circulation will be overestimated.

The steps in the calculation are as follows. An arbitrary value of bronchial blood flow $(\mathrm{QBr})$ is allocated by the program. If the blood oxygen contents of pulmonary artery, aortic, and pulmonary end capillary blood are respectively $\mathrm{CpaO}_{2}, \mathrm{CaOO}_{2}, \mathrm{Cc}^{\prime} \mathrm{O}_{2}$, then applying the Fick equation to the bronchial circulation,

$$
\mathrm{QBr}=\mathrm{Vo}_{2} \mathrm{Br} /\left(\mathrm{Cc}^{\prime} \mathrm{O}_{2}-\mathrm{CaOO}_{2}\right)
$$

where $\mathrm{Vo}_{2} \mathrm{Br}$ is the oxygen uptake in the bronchial circulation. After rearranging,

$$
\mathrm{Vo}_{2} \mathrm{Br}=\mathrm{QBr} \times\left(\mathrm{Cc}^{\prime} \mathrm{O}_{2}-\mathrm{CaOO}_{2}\right)
$$

Total oxygen uptake $\left(\mathrm{Vo}_{2} \mathrm{~T}\right)=\mathrm{Vo}_{2} \mathrm{Br}+$ pulmonary capillary oxygen uptake. Application of the Fick equation to. the pulmonary circulation gives

$$
\begin{gathered}
\text { Pulmonary capillary blood flow }= \\
\left(\mathrm{Vo}_{2} \mathrm{~T}-\mathrm{Vo}_{2} \mathrm{Br}\right) /\left(\mathrm{Cc}^{\prime} \mathrm{O}_{2}-\mathrm{CpaO}_{2}\right)
\end{gathered}
$$

Therefore, pulmonary capillary blood flow can be calculated for as many different bronchial circulation blood flows as desired.

The model is written in FORTRAN 04 to run on the hospital mainframe computer (Prime 750). A full listing is available from AB. It could easily be adapted to run on a microcomputer.

\section{Results}

HAEMODYNAMIC DATA

Table 2, in which the patients are arranged in ascending order of age, shows total oxygen uptake, the calculated oxygen contents of blood in aorta, pulmonary artery, pulmonary vein, and pulmonary end capillary, and the values of pulmonary blood flow and pulmonary vascular resistance.

We compared the calculated oxygen content of pulmonary end capillary blood and the measured oxygen content of pulmonary vein blood. The mean difference between the two was $0.29 \mathrm{ml} / \mathrm{dl}$ (SD 0.43) measured in air $(\mathrm{n}=5)$ and $0.27(\mathrm{SD} 0 \cdot 20)$ measured in oxygen $(n=7)$. The difference was statis-

\begin{tabular}{|c|c|c|c|c|c|c|c|c|c|}
\hline \multirow{2}{*}{$\begin{array}{l}\text { Patient } \\
\text { no }\end{array}$} & \multirow[b]{2}{*}{$\operatorname{Insp}$} & \multirow[b]{2}{*}{$\mathrm{VO}_{2}$} & \multicolumn{4}{|c|}{ Blood oxygen content } & \multirow[b]{2}{*}{$P A P$} & \multirow[b]{2}{*}{$Q p$} & \multirow[b]{2}{*}{$P V R$} \\
\hline & & & Ao & $P A$ & $P V$ & $P c^{\prime}$ & & & \\
\hline $1 \mathrm{a}$ & $100 \% \mathrm{O}_{2}$ & $\begin{array}{l}160 \\
173\end{array}$ & $\begin{array}{l}24 \cdot 34 \\
16.03\end{array}$ & $\begin{array}{l}23.00 \\
19.07\end{array}$ & $\begin{array}{l}24 \cdot 34 \\
20 \cdot 58\end{array}$ & $\begin{array}{l}24.79 \\
21.04\end{array}$ & 35 & $\begin{array}{l}9.0 \\
9.0\end{array}$ & 3.3 \\
\hline & $\begin{array}{ll}\mathrm{Mir} \\
100 \% \mathrm{O}_{2}\end{array}$ & $\begin{array}{l}173 \\
154\end{array}$ & 10.03 & $\begin{array}{l}19 \cdot 07 \\
21 \cdot 19\end{array}$ & $\begin{array}{l}20 \cdot 58 \\
22 \cdot 81\end{array}$ & $\begin{array}{l}21.04 \\
23 \cdot 16\end{array}$ & $\begin{array}{l}38 \\
39\end{array}$ & $\begin{array}{l}9.0 \\
7.8\end{array}$ & $\begin{array}{l}3 \cdot 7 \\
4 \cdot 4\end{array}$ \\
\hline 2 & $\begin{array}{l}\text { Air } \\
100 \% \mathrm{O}_{2}\end{array}$ & $\begin{array}{l}234 \\
236\end{array}$ & $\begin{array}{l}11 \cdot 11 \\
15 \cdot 53\end{array}$ & $\begin{array}{l}22 \cdot 15 \\
24 \cdot 36\end{array}$ & $\begin{array}{l}24 \cdot 73 \\
26 \cdot 67\end{array}$ & $\begin{array}{l}24.72 \\
26.91\end{array}$ & $\begin{array}{l}15 \\
15\end{array}$ & $\begin{array}{l}9 \cdot 1 \\
9 \cdot 3\end{array}$ & $\begin{array}{l}1.0 \\
1.0\end{array}$ \\
\hline 3 & $\begin{array}{l}\text { Air } \\
100 \% \mathrm{O}_{2}\end{array}$ & $\begin{array}{l}88 \\
88\end{array}$ & $15 \cdot 48$ & $\begin{array}{l}18.40 \\
20.95\end{array}$ & $\begin{array}{l}21 \cdot 23 \\
23 \cdot 14\end{array}$ & $\begin{array}{l}21 \cdot 14 \\
23 \cdot 37\end{array}$ & 23 & $\begin{array}{l}3.3 \\
3.2\end{array}$ & $\begin{array}{l}1.4 \\
3.4\end{array}$ \\
\hline 4 & Air & 162 & $18 \cdot 64$ & $20 \cdot 38$ & & $24 \cdot 23$ & 15 & $4 \cdot 2$ & 1.8 \\
\hline & $100 \% \mathrm{O}_{2}$ & 168 & $20 \cdot 88$ & $23 \cdot 60$ & $26 \cdot 40$ & $26 \cdot 42$ & 16 & 5.9 & $1 \cdot 1$ \\
\hline 5 & Air & 190 & $17 \cdot 07$ & $\begin{array}{l}19 \cdot 10 \\
23 \cdot 23\end{array}$ & $26 \cdot 00$ & $\begin{array}{l}26 \cdot 96 \\
29.20\end{array}$ & 33 & $\begin{array}{l}2.4 \\
2.6\end{array}$ & $\begin{array}{l}11.9 \\
11.4\end{array}$ \\
\hline 6 & $\begin{array}{l}100 \% \mathrm{O}_{2} \\
\text { Air }\end{array}$ & $\begin{array}{l}100 \\
166\end{array}$ & $\begin{array}{l}21.04 \\
16.94\end{array}$ & $\begin{array}{l}23 \cdot 23 \\
17 \cdot 31\end{array}$ & - & $\begin{array}{l}29 \cdot 29 \\
18 \cdot 81\end{array}$ & 51 & $12 \cdot 3$ & $\begin{array}{r}11.4 \\
3.0\end{array}$ \\
\hline & $100 \% \mathrm{O}_{2}$ & 148 & $19 \cdot 02$ & $19 \cdot 13$ & - & $20 \cdot 78$ & 50 & $10 \cdot 0$ & 3.7 \\
\hline 7 & Air & 154 & $24 \cdot 31$ & $27 \cdot 47$ & & $29 \cdot 31$ & 17 & $8 \cdot 3$ & 1.5 \\
\hline & $100 \% \mathrm{O}_{2}$ & 147 & 27.08 & $29 \cdot 56$ & $31 \cdot 37$ & 31.52 & 16 & 7.5 & 1.5 \\
\hline 8 & $\begin{array}{l}\text { Air } \\
100 \% 0\end{array}$ & $\begin{array}{l}240 \\
174\end{array}$ & $\begin{array}{l}25 \cdot 45 \\
28.71\end{array}$ & $\begin{array}{l}28 \cdot 96 \\
30 \cdot 31\end{array}$ & $\begin{array}{l}30 \cdot 81 \\
32 \cdot 54\end{array}$ & $\begin{array}{l}30.93 \\
33.14\end{array}$ & $\begin{array}{l}84 \\
74\end{array}$ & $\begin{array}{l}9 \cdot 4 \\
4 \cdot 7\end{array}$ & $\begin{array}{r}8.5 \\
14.3\end{array}$ \\
\hline
\end{tabular}
tically significant $(p=0.0004)$ according to

Table 2 Detailed results of the studies of haemodynamic function in which calculations of pulmonary blood flow ( $Q p$ ) and pulmonary vascular resistance (PVR) were based on pulmonary end capillary blood not pulmonary venous blood

Oxygen consumption $\left(\mathrm{Vo}_{2}\right), \mathrm{ml} / \mathrm{min}$ per $\mathrm{m}^{2}$; blood oxygen content, $\mathrm{ml} / \mathrm{dl}$; pulmonary artery pressure (PAP), mm $\mathrm{Hg}$; pulmonary blood flow (Qp), $1 / \mathrm{min}$ per $\mathrm{m}^{2}$; pulmonary vascular resistance (PVR), $\mathrm{mm} \mathrm{Hg.} \mathbf{1}^{-1} \cdot \mathrm{min} \cdot \mathrm{m}^{2}$. 
Figure 2 Comparison of oxygen contents of pulmonary venous and pulmonary end capillary blood. This plot shows that estimates of pulmonary end capillary blood oxygen content were

systematically slightly greater than measured pulmonary venous blood oxygen content. Closed circles are measurements in air and open circles are measurements in $100 \%$ oxygen. The dotted line is the mean of all twelve points.
Figure 3 Comparison of differences in the pulmonary arteriovenous oxygen content when pulmonary end capillary blood and pulmonary venous blood are used. This plot shows that, because the arteriovenous oxygen content difference is so small, the minor discrepancies shown in figure 2 result in large discrepancies in the oxygen content differences. Closed circles are measurements in circles are measuremen measurements in 100\% oxygen. The dotted line is the mean of all twelve points.

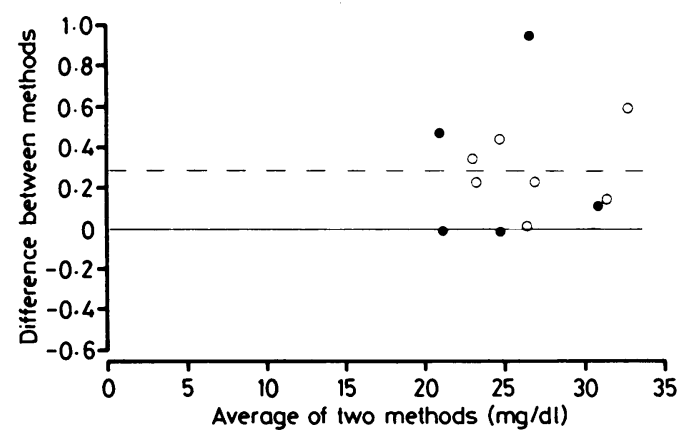

repeated measures analysis of variance, allowing for missing data. ${ }^{18}$ Figure 2 shows the error and bias. If pulmonary end capillary blood was paired with pulmonary artery blood, the mean (SE) of the blood oxygen content differences across the pulmonary circulation was 2.78 $(0.52) \mathrm{ml} / \mathrm{dl}$; if pulmonary vein blood was used instead, the corresponding result was 2.47 $(0.46) \mathrm{ml} / \mathrm{dl}$. The mean percentage difference between these two sets of values was 14.5 (3.8) (range -3.2 to $33.9 \%$ ). Figure 3 shows the error and bias.

Figure 4 shows the results of the bronchial circulation modelling. This shows the mean and $95 \%$ confidence intervals of the percentage error in pulmonary blood flow caused by unsuspected bronchial blood flow of 0.1-1.0 1/ min per $\mathrm{m}^{2}$. The results for a normal subject are shown for comparison. There is considerable individual variation; for a bronchial flow of $0.5 \mathrm{l} / \mathrm{min}$ per $\mathrm{m}^{2}$, the error could have been as much as $32 \%$ or as little as $1.4 \%$. The lower the total oxygen uptake, and the lower the aortic blood oxygen content, the greater the errors that were encountered.

\section{FOLLOW UP DATA}

We were able to compare measurements of pulmonary vascular resistance with lung structure in two patients. Patient 5 had Heath Edwards late grade III disease (her pulmonary vascular resistance was 10.5 units in air) and patient 6 had only grade I/II with a pulmonary vascular resistance on air of 3.7 units. Patient 1 had a Mustard's procedure, with closure of the ventricular septal defect and has done well postoperatively. Patients 2, 3, 4, and 7 are awaiting corrective operation. Patient 8 had a palliative Mustard's procedure, and a postoperative study showed a pulmonary vascular resistance of 9.9 units in air.

\section{Discussion}

The conventional solution of the Fick equation for organ blood flow assumes that either the concentration difference or the flow rate or

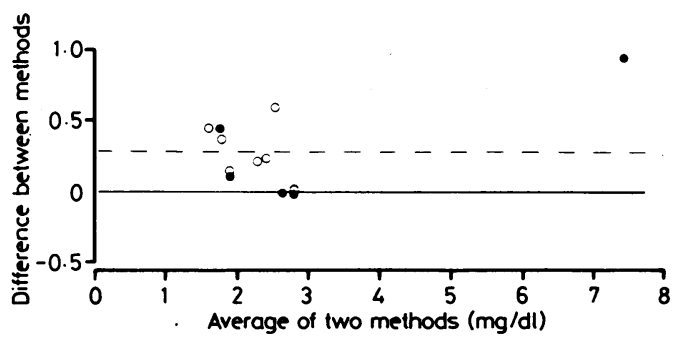

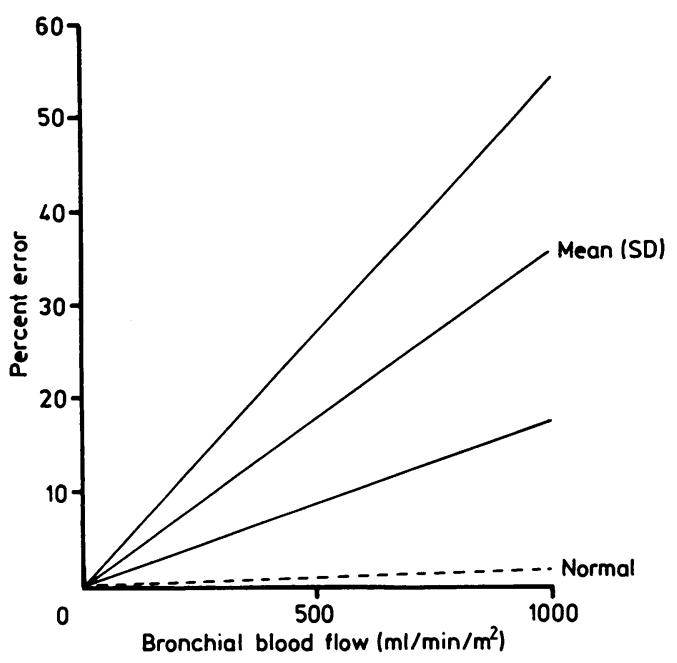

Figure 4 Results of the bronchial circulation model. The mean and $95 \%$ confidence intervals for the overestimate of pulmonary blood flow are plotted against bronchial blood flow. The dotted line shows equivalent results for a control.

both are constant while the measurement is made. ${ }^{9}$ This is rarely if ever true. The smaller the arteriovenous concentration difference, the greater the error that these assumptions produce. ${ }^{9}$ This paper highlights two particular problems in the measurement of pulmonary vascular resistance in transposition of the great arteries, namely the difficulty of ascertaining the true pulmonary vein blood oxygen content and the possible role of the bronchial circulation.

The lungs are drained by four pulmonary veins. Even in the supine position during cardiac catheterisation there are likely to be regional variations in pulmonary gas exchange. This could result in variations in the oxygenation of blood in the four pulmonary veins, of which one only is routinely sampled. Blood flow is pulsatile at all levels of the pulmonary circulation, ${ }^{19}$ and hence red cell capillary transit times will vary with the phase of the cardiac and respiratory cycles. This will result in small phasic alterations in blood oxygen content with time. Slow withdrawal of a systemic blood sample would partially overcome these effects if there were no intracardiac shunts. But this procedure is open to the criticism that it produces a time average sample at a point not a volume average at the area of sampling. ${ }^{9}$ In transposition the choices are either to use a sample from a single pulmonary vein or to use the alveolar air equation to predict pulmonary end capillary oxygen content. This latter approach assumes a uniform distribution of ventilation to perfusion ratios within the lung, but, particularly if the patient is ventilated on $100 \%$ oxygen, even large inequalities will not significantly affect the calculated oxygen content. This equation thus provides a way of partially overcoming regional differences but takes no account of the anatomical intrapulmonary shunt. There is good agreement between the end capillary and pulmonary vein blood, as found in other patients with congenital heart disease. ${ }^{15}$ However, even a minor systematic difference between the two, results in big differences in calculated flow if the 
Figure 5 Lowest pulmonary vascular resistance (PVR, $\mathrm{mm}$ Hg.l '.min. $\mathrm{m}^{2}$ ) plotted against bronchial blood flow $Q B r, \mathrm{ml} / \mathrm{min} / \mathrm{m}^{2} . M$ is the actual measurement made in pulmonary end capillary blood. The difficulties of getting a true pulmonary vein sample were estimated as likely to understimate true PVR by $15^{\circ}{ }_{0}$ (see text; plotted as $Q B r=0.0)$. The remaining points are based on the additional effects of the bronchial circulation which were modelled as described.

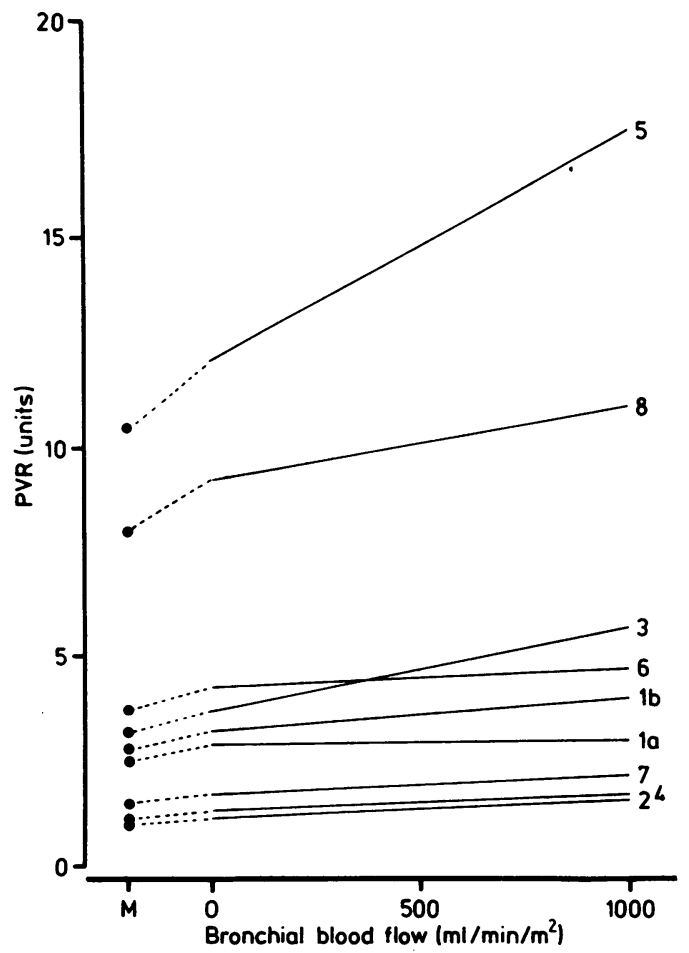

arteriovenous blood oxygen content difference is small.

The nature of bronchial blood flow in this condition may also lead to inaccuracy. Normally, bronchial artery blood is nearly fully saturated and can take up far less oxygen than pulmonary artery blood. In transposition this is not the case. Normal bronchial blood flow has been estimated as $50-100 \mathrm{ml} / \mathrm{min}$ per $\mathrm{m}^{2} .{ }^{20} \mathrm{Our}$ computer model has shown that even modest increases in bronchial blood flow can result in significant overestimation of pulmonary blood flow.

Other workers have confirmed that the Fick method overestimates pulmonary blood flow. ${ }^{112}$ Dye dilution or thermodilution with pulmonary artery sampling will not be affected by bronchial blood flow, ${ }^{11}$ but such measurements are difficult to interpret in infants with intracardiac shunting. Pulmonary blood flow has been measured from angiograms $^{122122}$ but only in infants with no ventricular septal defect. The dose of contrast necessary precludes repeated measurements to assess any response to vasodilators. It is therefore likely that the Fick method will continue to be used and we believe it provides useful information if correctly interpreted. The follow up data, although incomplete, nevertheless support the view that resistance measurements may be valuable. High values were found with severe pulmonary vascular disease (patient 5) or a high resistance after palliative operation (patient 8), when the more normal pattern of oxygen saturations allows greater certainty about the measurements. Low values were found with only mild pulmonary vascular disease (patient 6 ) or a good outcome after operation (patient 1).

These data suggest that the measured lowest pulmonary vascular resistance is the "best case". The "worst case" is found by modelling the effects of the bronchial blood circulation and adding $15 \%$ for the effects of the problems of pulmonary venous sampling. Figure 5 shows this approach in our patients. Pulmonary vascular resistance is plotted against bronchial blood flow, to show the "best" and "worst" cases. In many patients the decision to operate can be reached without recourse to these calculations. In patients where there is doubt, we believe that such calculations may be helpful, permitting the importance (or otherwise) of the uncertainties in the conventional calculations to be modelled. In our laboratory, a lowest resistance of 6.5 units was associated with inoperable pulmonary vascular disease ${ }^{23}$ So if the "best case" is significantly greater than 6.5 units, then only palliative procedures should be offered; if the "worst case" is less than 6.5 units, then corrective operation can be considered. If the possible range of resistance spans 6.5 units, then a lung biopsy is needed to assess the disease.

1 Ferencz P. Transposition of the great vessels. Circulation 1966;33:232-41.

2 Newfeld EA, Paul MH, Muster AJ, Idriss FS. Pulmonary vascular disease in transposition of the great vessels and intact ventricular septum. Circulation 1979;59:525-30.

3 Haworth SG, Radley-Smith R, Yacoub M. Lung biopsy findings in transposition of the great arteries with ventricular septal defect: potentially reversible pulmonary vascular disease is not always synonymous with operability. J Am Coll Cardiol 1987;9:327-33.

4 Wagenvoort CA, Nauta J, van der Schaar PJ, Weeda HWH, Wagenvoort $\mathrm{N}$. The pulmonary vasculature in complete transposition of the great vessels, judged from lung biopsies. Circulation 1968;38:746-54.

5 Clarkson PM, Neutze JM, Wardill JC, Barratt-Boyes BG. The pulmonary vascular bed in patients with complete transposition of the great arteries. Circulation 1976; 53:539-43.

6 Edwards WD, Edwards JE. Hypertensive pulmonary vascular disease in d-transposition of the great arteries. $\mathrm{Am} \mathrm{J}$ Cardiol 1978;41:921-4.

7 Plauth WH, Nadas AS, Bernhard WF, Fyler DC. Changing hemodynamics in patients with transposition of the great arteries. Circulation 1970;42:131-42.

8 Viles PH, Ongley PA, Titus JL. The spectrum of pulmonary vascular disease in transposition of the great arteries. Circulation 1969;40:31-41.

9 Visscher MB, Johnson JA. The Fick principle: analysis of potential errors in its conventional application. $J A p p l$ Physiol 1953;5:635-8.

10 Mesel E. Direct measurement of intracardiac blood flow in dogs with experimental ventricular septal defects. Circ Res 1970;27:1033-45.

11 Keane JF, Ellison RC, Rudd M, Nadas AS. Pulmonary blood flow and left ventricular volumes in transposition of blood flow and left ventricular volumes in transposition of the great arteries

12 Lakier JB, Stanger P, Heymann MA, Hoffman JIE, Rudolph AM. Early onset of pulmonary vascular obstruction in patients with aortopulmonary transposition an intact ventricular septum. Circulation 1975;51:875-80.

13 Davies NJH, Denison DM. The measurement of metabolic gas exchange and minute volume by mass spectrometry alone. Respir Physiol 1979;36:261-7.

14 Davies NJH, Shinebourne EA, Scallan MJ, Sopwith TA, Denison DM. Pulmonary vascular resistance in children with congenital heart disease. Thorax 1984;39:895-900.

15 Bush A, Busst CM, Booth K, Knight WB, Shinebourne EA Does prostacyclin enhance the selective pulmonary vasodilator effect of oxygen in children with congenital vasodilator effect of oxygen in children wirculation 1986;74:135-44.

16 Kelman GR. Digital computer subroutine for the conversion of oxygen tension into oxygen saturation. J Appl Physiol of oxygen tension

17 Botenga ASJ. Selective bronchial and intercostal arteriography. Leiden, The Netherlands: Stenvert Kroese NV,

18 Dixon WJ, ed.BMDP statistical software vol 2. Los Angeles: University of California Press, 1988

19 Morkin E, Collins JA, Goldman HS, Fishman AP. Pattern of blood flow in the pulmonary veins of the dog. $J$ Appl Physiol 1965;20:1118-28.

20 Magno MG, Fishman AP. Origin, distribution and blood flow of bronchial circulation in anaesthetised sheep. $J$ Appl Physiol 1982;53:272-9.

21 Graham TP, Jarmakani JM, Canent RV, Jewett PH. Quantification of left heart volume and systolic output in transposition of the great arteries. Circulation 1971;44:899-909.

22 Tynan M. Transposition of the great arteries. Circulation 1972;46:809-15.

23 Bush A, Busst CM, Haworth SG, et al. Correlations of lung morphology, pulmonary vascular resistance, and outcome in children with congenital heart disease. Br Heart J 1988;59:480-5. 